\section{PCV chemotherapy for recurrent glioblastoma multiforme}

Article abstract-The authors evaluated response, time to progression (TTP), survival, prognostic factors, and toxicity in 63 patients with a recurrent glioblastoma multiforme treated with procarbazine, lomustine, and vincristine (PCV) chemotherapy. Complete and partial response was observed in two $(3 \%)$ and five patients (8\%). In 16 patients $(25 \%)$, stable disease was observed. Median TTP and survival were 13 and 33 weeks. Age $<40$ years and Karnofsky Performance Status $\geq 90$ were associated with longer TTP and survival. PCV treatment was generally well tolerated.

NEUROLOGY 2001;56:118-120

\begin{abstract}
A.C. Kappelle, MD; T.J. Postma, MD; M.J.B. Taphoorn, MD; G.J. Groeneveld, MD; M.J. van den Bent, MD; C.J. van Groeningen, MD; B.A. Zonnenberg, MD; K.C.A. Sneeuw, MSc; and J.J. Heimans, MD
\end{abstract}

Despite different treatment options such as reoperation, reirradiation, gene therapy, immune therapy, and chemotherapy, no standard treatment regimen with proven effectiveness and acceptable toxicity is yet available for patients with recurrent glioblastoma multiforme (rGBM), and the prognosis remains poor. ${ }^{1,2}$ Many chemotherapeutic agents, either as single agents or in combination chemotherapy regimens, have been used to treat (recurrent) malignant gliomas. The first results of treatment with procarbazine, lomustine (CCNU), and vincristine (PCV) chemotherapy for malignant brain tumors were reported in $1975 .{ }^{3}$ Since then several studies have been published on PCV chemotherapy in patients with (recurrent) glioma, including various brain tumor histologies. However, survival is partly dependent on histology; this makes it difficult to draw firm conclusions from literature data as to the efficacy of a given treatment in recurrent brain tumors.

In this multicenter retrospective study, we report the effects of PCV chemotherapy in 63 patients with a rGBM. We evaluated response rate, time to progression, survival, prognostic factors, and toxicity.

Methods. Only patients with a histologically verified diagnosis of a GBM, either initially or at recurrence, were included. Radiologic evidence (measurable with CT or MRI) of tumor recurrence after prior therapy, or residual disease after prior reresection, had to be present. Other inclusion criteria were age 18 to 75 years, Karnofsky performance status $(\mathrm{KPS}) \geq 60$ and life expectancy greater than 3 months. Exclusion criteria were administration of other antineoplastic drugs during the study period, concurrent radiotherapy, cardiac failure, and sensory or motor neuropathy grade 2 or worse according to National Cancer

From the Departments of Neurology and Medical Oncology (Drs. Kappelle, Postma, van Groeningen, and Heimans), University Hospital Vrije Universiteit, Amsterdam; Departments of Neurology and Medical Oncology (Drs. Taphoorn, Groeneveld, and Zonnenberg) University Medical Center, Utrecht; Department of Neuro-oncology (Dr. van den Bent) University Hospital Rotterdam/Daniel Den Hoed Cancer Center, Rotterdam; and Comprehensive Cancer Center (K.C.A. Sneeuw), Amsterdam, the Netherlands. Received April 17, 2000. Accepted in final form August 24, 2000.

Address correspondence and reprint requests to Dr. T.J. Postma, Department of Neurology, University Hospital Vrije Universiteit, PO Box 7057, 1007 MB Amsterdam, the Netherlands; e-mail: TJ.Postma@azvu.nl
Institute of Canada-Common Toxicity Criteria (NCICCTC) criteria before the start of PCV chemotherapy.

Standard or intensified (in the first nine patients in one of the participating centers) PCV chemotherapy was administered in a 42-day cycle, as described elsewhere. ${ }^{4,5} \mathrm{Re}-$ sponse was assessed according to the criteria of Macdonald et al., ${ }^{6}$ using the same radiologic modality (CT or MRI) per patient. Standard laboratory tests were performed at baseline and during therapy. Toxicity was scored according to NCIC-CTC after each cycle.

Statistical analysis was performed for the evaluation of time to progression (TTP) and survival, measured from the start of PCV chemotherapy (Kaplan-Meier method). Subgroups of patients based on age, KPS, histology, and interval between initial diagnosis and recurrence were formed. To evaluate the effects of these prognostic factors on TTP and survival, hazard ratios were estimated using Cox proportional hazards model.

Results. Patient characteristics are summarized in table 1. From 1994 to 1998, 63 patients (median age 46 years) were included in this study. At the first presentation, 14 patients had undergone a biopsy, and 49 patients had undergone a maximal resection. All patients were treated with radiotherapy postsurgery. Six patients had been treated with reirradiation for recurrent disease before PCV chemotherapy. Twenty patients were treated with prior chemotherapy. Reresections were performed in 26 patients. All patients used antiepileptic drugs, and 47 of the 63 patients used dexamethasone (median $6 \mathrm{mg}$, range 2 to $22.5 \mathrm{mg}$ ) at the time of recurrence.

Outcome. PCV chemotherapy resulted in complete response $(\mathrm{CR})$ in two patients $(3 \%)$, partial response $(\mathrm{PR})$ in five patients $(8 \%)$, and stable disease (SD) in 16 patients (25\%). The median TTP and survival for the entire patient group were 13 and 33 weeks. The median TTP and survival for the patients with CR, PR, or SD were 39 and 44 weeks, whereas in the group of patients with PD, the TTP was 13 weeks and the survival was 26 weeks. Six-month survival after the start of PCV chemotherapy for the entire group was $68 \%$, 1-year survival was $18 \%$, and 2 -year survival was $5 \%$. Progression-free survival at 6 months (APF6) was $29 \%$. No difference in response was found in patients treated with intensified or standard PCV. In chemonaive patients, $44 \%$ showed a response or stable disease after PCV, compared with $20 \%$ in patients with prior chemotherapy ( $p=0.06$ ). Median survival was comparable in patients with or without prior reresection. 
Table 1 Patient characteristics

\begin{tabular}{lc}
\hline Characteristics & Results \\
\hline Sex, M/F & $47 / 16$ \\
Age, y, median (range) & $46(19-73)$ \\
KPS, median (range) & $80(60-100)$ \\
Initial histology, lower grade tumor/GBM & $19 / 44$ \\
Time between initial treatment and start of & $39(9-572)$ \\
$\quad$ PCV, wk, median (range) & \\
$\quad<52$ wk, n & 38 \\
$\quad \geq 52$ wk, n & 25 \\
Courses PCV, n, median (range) & $2(1-7)$ \\
Previous chemotherapy, n & 20 \\
Paclitaxel & 10 \\
Temozolomide & 4 \\
Cisplatin/ifosfamide & 2 \\
Carboplatin/etoposide & 1 \\
Topotecan & 1 \\
Suramin & 2 \\
Previous reirradiation, n & 6 \\
Previous reresection, $\mathrm{n}$ & 26 \\
\hline KPS Karnofky Perfor & \\
\hline
\end{tabular}

KPS $=$ Karnofsky Performance Status; GBM = glioblastoma multiforme; $\mathrm{PCV}=$ procarbazine, $\mathrm{CCNU}$, vincristine.

Prognostic factors. Univariate analysis (table 2) showed a higher response rate and a longer median survival in the patient group younger than 40 years of age or with a KPS $\geq 90$. Patients with a prior lower grade tumor had a similar response rate but a longer survival, compared with patients with a prior GBM. Multivariate analysis (table 3), testing the independent effects of the four prognostic factors on the TTP and survival, showed that none of the prognostic factors were significantly associated with either survival or TTP, although substantially decreased risks (hazard ratios) of progression and death were observed for patients younger than 40 years of age or with KPS $\geq 90$.

Toxicity. Hematologic toxicity up to grade 2 was observed frequently. However, reduction of PCV dosage due to leucopenia was necessary in only two patients. Other toxicities, including nausea, vomiting, asthenia, and (vincristine-induced) peripheral neuropathy, were mild to moderate in most cases.
Discussion. In this article, we report our results of treatment with PCV chemotherapy in patients with a recurrent GBM. The 36\% response rate (including $\mathrm{SD}$ ) in our patient group, and the 1-year overall survival of $18 \%$ are comparable with the results of other studies. ${ }^{1,2}$ However, the median TTP (13 weeks) and median survival (33 weeks) in our study are of longer duration than the reported median TTP of 9 weeks and median survival of 25 weeks in the study by Wong et al., ${ }^{2}$ in which 225 patients with rGBM treated according to several chemotherapeutic phase II trials were included. The observed proportion of patients alive and progression free at 6 months (APF6) (29\%) in our study compares favorably with the APF6 with temozolomide (21\%) or procarbazine monotherapy (9\%) in patients with rGBM at first relapse in a recent large randomized trial. ${ }^{7}$

Among prognostic factors investigated in our study, age $<40$ years and a KPS $\geq 90$ were associated with a favorable outcome, although not significant in the multivariate analysis.

Treatment with PCV chemotherapy was well tolerated in terms of toxicity, and no serious adverse events were observed. Toxicity of PCV chemotherapy was similar to that of earlier studies described in literature. ${ }^{8,9}$ Initially, in one center, the intensified PCV therapy was applied, but this was abandoned after the observation of possible central neurotoxicity due to this treatment. ${ }^{10}$

Our study certainly has its limitations. We did not perform biopsy or reresection in all patients with prior GBM to confirm tumor recurrence and to exclude radionecrosis. However, in one of the participating centers, ${ }^{201}$ thallium SPECT scans were made routinely before and during chemotherapy, and in all evaluable scans (in 25 patients), thallium uptake was observed before PCV chemotherapy, suggesting the existence of viable tumor rather than radionecrosis. Another limitation of our study is that we did not perform routinely quality of life assessments during therapy, although we have the impression that PCV chemotherapy was well tolerated. Furthermore, it is impossible from this study to verify exactly the effects of treatment with PCV chemotherapy on rGBM because it is a single-arm phase II trial.

Table 2 Univariate associations between patient characteristics and response rate, median time to progression (TTP), and survival

\begin{tabular}{|c|c|c|c|c|}
\hline Patient characteristics & $\mathrm{CR}, \mathrm{PR}$, or $\mathrm{SD}, \%$ & Progressive disease, $\%$ & TTP, wk & Survival, wk \\
\hline \multicolumn{5}{|l|}{ Age, $\mathrm{y}$} \\
\hline$<40 / \geq 40$ & $45 / 33$ & $55 / 67$ & $14 / 13$ & $41 / 30$ \\
\hline \multicolumn{5}{|l|}{ KPS } \\
\hline$\geq 90 /<90$ & $75 / 23$ & $25 / 77$ & $26 / 13$ & $44 / 30$ \\
\hline \multicolumn{5}{|l|}{ Prior histology } \\
\hline Interval from initial diagnosis to recurrence $\geq 52 /<52 \mathrm{wk}$ & $36 / 37$ & $64 / 63$ & $13 / 13$ & $36 / 30$ \\
\hline
\end{tabular}

$\mathrm{CR}=$ complete response; $\mathrm{PR}=$ partial response; $\mathrm{SD}=$ stable disease. 


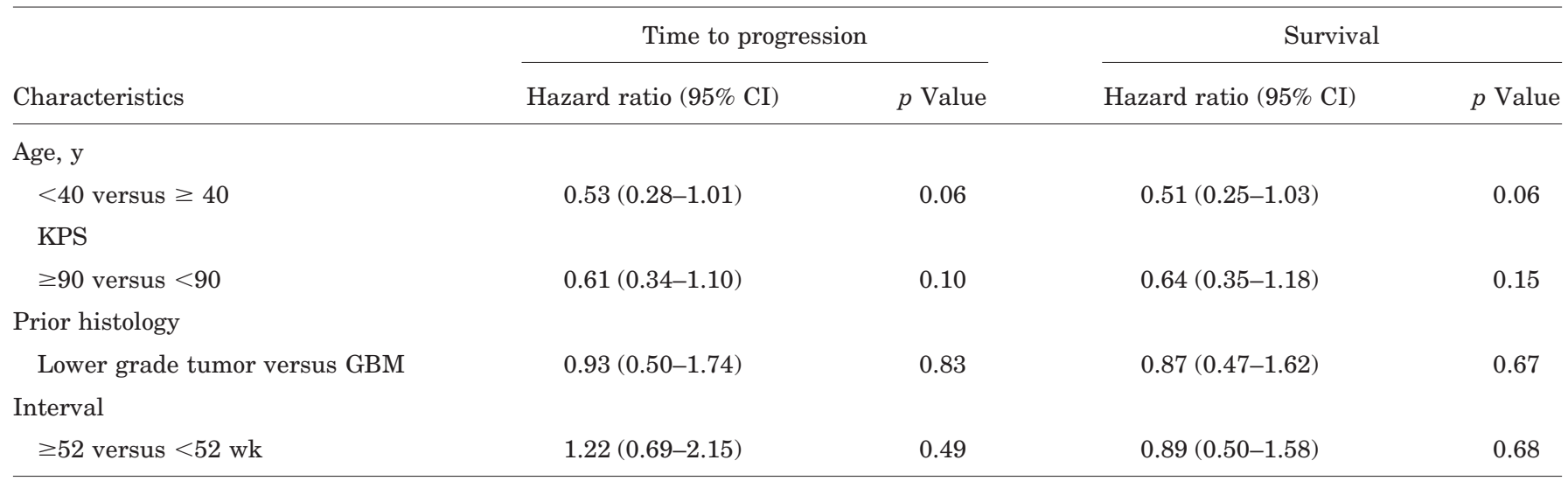

KPS $=$ Karnofsky Performance Status; GBM = glioblastoma multiforme .

We conclude that PCV chemotherapy is a fair chemotherapeutic alternative for patients with recurrent GBM with moderate antineoplastic activity and acceptable toxicity. However, the true value of PCV chemotherapy in this setting can only be evaluated properly in a randomized phase III study. Unfortunately, the results of our study and others strongly suggest that current treatments for patients with rGBM are still inadequate. Better treatment strategies to improve survival and quality of life in these patients are needed.

\section{References}

1. Rajan B, Ross G, Lim CC, et al. Survival of patients with recurrent glioma as a measure of treatment efficacy: prognostic factors following nitrosourea chemotherapy. Eur J Cancer 1994;30A:1808-1815.

2. Wong ET, Hess KR, Gleason MJ, et al. Outcomes and prognostic factors in recurrent glioma patients enrolled onto phase II clinical trials. J Clin Oncol 1999;17:2572-2578.

3. Gutin PH, Wilson CB, Kumar ARV, et al. Phase II study of procarbazine, CCNU, and vincristine combination chemother- apy in the treatment of malignant brain tumors. Cancer 1975; 35:1398-1404

4. Levin VA, Edwards MS, Wright DC, et al. Modified procarbazine, CCNU and vincristine (PCV) combination chemotherapy in the treatment of malignant brain tumors. Cancer Treat Rep 1980;64:237-241.

5. Cairncross G, Macdonald D, Ludwin S, et al. Chemotherapy for anaplastic oligodendroglioma. J Clin Oncol 1994;12:2013-2021.

6. Macdonald DR, Cascino TL, Schold SC Jr, Cairncross JG. Response criteria for phase II studies of supratentorial malignant glioma. J Clin Oncol 1990;8:1277-1280.

7. Yung A, Levin V, Albright R, et al. Randomized trial of temodal versus procarbazine in glioblastoma multiforme at first relapse. J Neurooncol 1998;39:102. Abstract.

8. Levin VA, Wara WM, Davis RL, et al. Phase III comparison of $\mathrm{BCNU}$ and the combination of procarbazine, CCNU, and vincristine administered after radiotherapy with hydroxyurea for malignant gliomas. J Neurosurg 1985;63:218-223.

9. van den Bent MJ, Kros JM, Heimans JJ, et al. Response rate and prognostic factors of recurrent oligodendroglioma treated with procarbazine, CCNU and vincristine chemotherapy. Neurology 1998;51:1140-1145.

10. Postma TJ, van Groeningen CJ, Witjes RJGM, Weerts JGE, Kralendonk JH, Heimans JJ. Neurotoxicity of combination chemotherapy with procarbazine, CCNU and vincristine (PCV) for recurrent glioma. J Neurooncol 1998;38:69-75. 


\section{Neurology}

\section{PCV chemotherapy for recurrent glioblastoma multiforme}

A.C. Kappelle, T.J. Postma, M.J.B. Taphoorn, et al.

Neurology 2001;56;118-120

DOI 10.1212/WNL.56.1.118

\section{This information is current as of January 9, 2001}

\section{Updated Information \& Services}

References

Citations

Subspecialty Collections

Permissions \& Licensing

Reprints including high resolution figures, can be found at: http://n.neurology.org/content/56/1/118.full

This article cites 10 articles, 4 of which you can access for free at: http://n.neurology.org/content/56/1/118.full\#ref-list-1

This article has been cited by 12 HighWire-hosted articles: http://n.neurology.org/content/56/1/118.full\#\#otherarticles

This article, along with others on similar topics, appears in the following collection(s):

\section{All Oncology}

http://n.neurology.org/cgi/collection/all_oncology

Chemotherapy-tumor

http://n.neurology.org/cgi/collection/chemotherapytumor

Primary brain tumor

http://n.neurology.org/cgi/collection/primary_brain_tumor

Information about reproducing this article in parts (figures,tables) or in its entirety can be found online at:

http://www.neurology.org/about/about_the_journal\#permissions

Information about ordering reprints can be found online: http://n.neurology.org/subscribers/advertise

Neurology ${ }^{\circledR}$ is the official journal of the American Academy of Neurology. Published continuously since 1951, it is now a weekly with 48 issues per year. Copyright. All rights reserved. Print ISSN: 0028-3878. Online ISSN: 1526-632X.

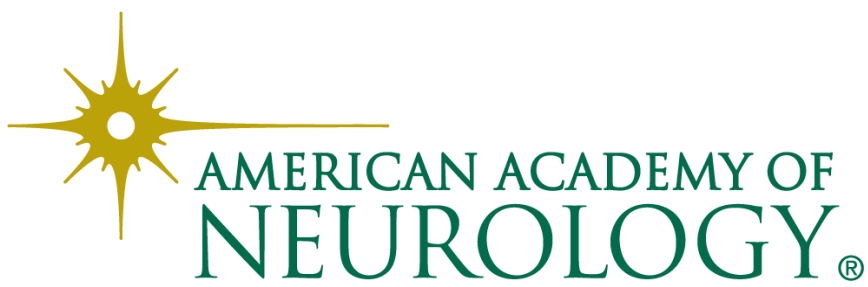

